\title{
DYNAMIC TESTING OF PRECAST, POST-TENSIONED ROCKING WALL SYSTEMS WITH ALTERNATIVE DISSIPATING SOLUTIONS
}

\author{
D. Marriott ${ }^{1}$, S. Pampanin ${ }^{1}$, D. Bull ${ }^{1}$ \\ and A. Palermo ${ }^{2}$
}

\begin{abstract}
During the past two decades, the focus has been on the need to provide communities with structures that undergo minimal damage after an earthquake event while still being cost competitive. This has led to the development of high performance seismic resisting systems, and advances in design methodologies, in order respect this demand efficiently.

This paper presents the experimental response of four pre-cast, post-tensioned rocking wall systems tested on the shake-table at the University of Canterbury. The wall systems were designed as a retrofit solution for an existing frame building, but are equally applicable for use in new design. Design of the wall followed a performance-based retrofit strategy in which structural limit states appropriate to both the post-tensioned wall and the existing building were considered.

Dissipation for each of the four post-tensioned walls was provided via externally mounted devices, located in parallel to post-tensioned tendons for re-centring. This allowed the dissipation devices to be easily replaced or inspected following a major earthquake. Each wall was installed with viscous fluid dampers, tension-compression yielding steel dampers, a combination of both or no devices at all thus relying on contact damping alone. The effectiveness of both velocity and displacement dependant dissipation are investigated for protection against far-field and velocity-pulse ground motion characteristics.

The experimental results validate the behaviour of 'Advanced Flag-Shape' rocking, dissipating solutions which have been recently proposed and numerically tested. Maximum displacements and material strains were well controlled and within acceptable bounds, and residual deformations were minimal due to the re-centring contribution from the post-tensioned tendons. Damage was confined to inelastic yielding (or fluid damping) of the external dampers.
\end{abstract}

\section{INTRODUCTION}

In recent literature the performance of structures with unbonded post-tensioning undergoing controlled rocking at discrete locations has highlighted significant improvements to their structural performance when compared to equivalently reinforced monolithic counterparts; for use in buildings (Priestley et al. 1999), (Kurama 2002), (Pampanin 2005) and bridge systems (Mander and Cheng 1997), (Palermo et al. 2005). This enhanced performance relates to inelastic deformation being lumped to a number of specifically designed and detailed, discrete rocking interfaces. An example is presented in Figure 1 below where a post-tensioned pre-cast rocking wall unit is installed with replaceable externally mounted mild steel dampers. The dampers are designed to yield in tension and compression only (defined as TCY mild steel dampers) and are restrained against buckling. Upon loading of the wall the rocking of the interface (Figure 1, Right) elongates both the steel dampers and post-tensioned tendons in tension. The ratio of the prestressed reinforcement (and axial load) to the non-prestressed reinforcement dictates the energy dissipation and re-centring of the wall system - these two parameters give an indication of the expected maximum displacement and residual deformation of the wall system following dynamic response. This technology has been codified both internationally (ACI:T1.2-03 2007) and nationally in Appendix B of the New Zealand Concrete Standard (NZS3101 2006) and is termed Hybrid or Controlled Rocking Technology.

Previous experimental work specifically concerned with unbonded post-tensioned wall systems dates back to (Mueller 1986) who tested a series of pre-cast walls for use in regions of moderate seismicity. The experimental testing exhibited a significant amount of stiffness degradation and energy dissipation. As part of Phase III of the United States PRESSS program (PREcast Seismic Structural Systems (Priestley et al. 1999)), a $60 \%$ scale prototype building was constructed and tested (Pseudo-dynamic testing) comprising of a precast posttensioned coupled wall system orthogonal to a hybrid moment resisting frame system. The coupled walls experienced only loss of cover concrete to the toe regions while dissipation via U-Shaped Flexure Plates (UFP) was found to be very stable after being tested to $150 \%$ of the design level ground motion.

\footnotetext{
${ }^{1}$ University of Canterbury, Christchurch, New Zealand.

${ }^{2}$ Technical University of Milan, Italy.
} 
Further to the United States PRESSS program, a significant amount of work (largely analytical) was undertaken to further understand the behaviour of unbonded post-tensioned precast wall systems for use in seismic regions (Kurama et al. 1998a), (Kurama et al. 1998b). This work was extended to include the response of hybrid rocking wall systems with externally mounted viscous dampers (Kurama 2000), originally limited to internally grouted mild steel reinforcement (Kurama 2002).

Past research at the University of Canterbury has also investigated similar systems with minor variations on the detailing of the precast wall unit - specifically concerning protection of the rocking toe region (Rahman and Restrepo 2000), (Holden 2001).

While a significant amount of analytical and experimental research has been carried out to quantify the performance of post-tensioned wall systems, the response has yet to be con- firmed through dynamic testing. Furthermore, issues relating to the energy dissipation occurring due to the rocking impact of the wall-foundation (defined as contact damping) can only be addressed through such test methods. In fact, some uncertainties exist in design in order to determine the total damping (hysteretic plus contact) to be assigned directly to the rocking mechanism of such systems.

Moreover, while viscous dampers have been proposed for hybrid systems, the combination of both viscous and mild steel devices for protection against both near-field and far-field earthquake ground motions has been previously limited to analytical studies (Kam et al. 2007). This paper attempts to address these issues and to quantify the dynamic response, from a performance-based design point of view, applicable to a retrofit intervention of an existing frame building or for new design.

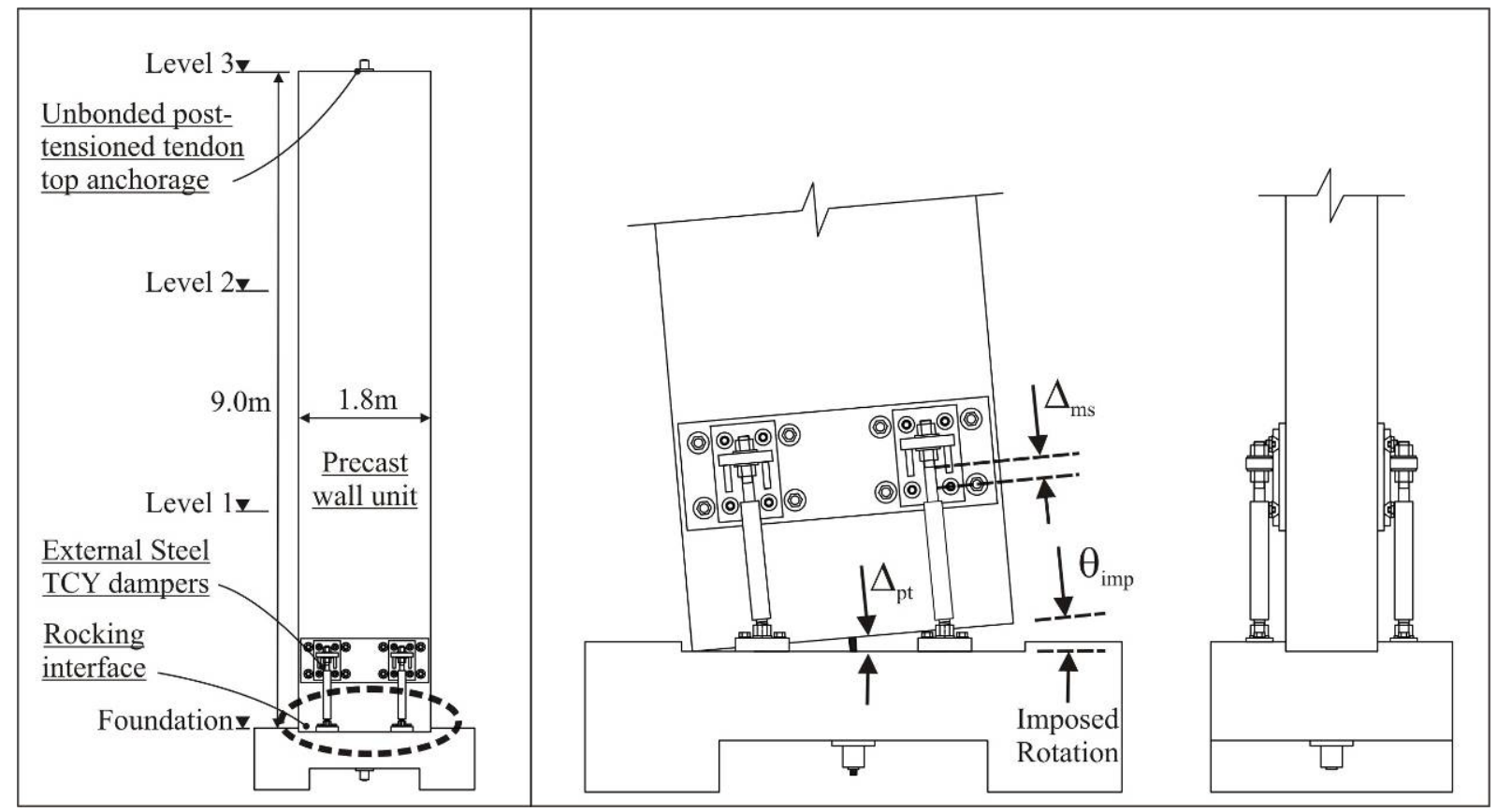

Figure 1. Post-tensioned precast rocking wall system with externally mounted mild steel dampers (Left), Mechanics of a controlled rocking wall system (Right).

\section{PERFORMANCE BASED DESIGN OF PRECAST POST-TENSIONED WALLS}

Performance-based design has emerged as a more rational approach for the design of structures, furthermore it is now recognised that emphasis should be placed on the displacement/deformation response of a structure as opposed to its strength. Hybrid systems with controlled rocking mechanisms are well suited to such a design methodology as material strain limits can be controlled with greater confidence when compared to traditional reinforced concrete monolithic solutions.

Performance-based design sets out to assign structural performance levels (which encompass a series of structural limit states, in turn defined by material limit states) to seismic hazards which are defined by earthquake intensities, generally in the form of Peak Ground Acceleration (PGA) and also influenced by the importance of the structure. Assigning a structural performance level to a seismic hazard defines a structural performance objective. This concept is summarised as a chart in Figure 2 (Left). The idea of a performance-based design is that multiple performance objectives are defined for a single structure to ensure a higher level of performance against a spectrum of anticipated earthquake intensities (seismic hazards). Each structural performance level can be assigned to a corresponding seismic intensity, resulting in a multi-level design spectrum, defining a performance based design matrix. An example of such a design matrix is presented in Figure 2 (Right), reproduced from the SEAOC Bluebook (SEAOC 1999), illustrating three sets of performance objectives (one basic objective and two enhanced objectives for greater structural importance). 


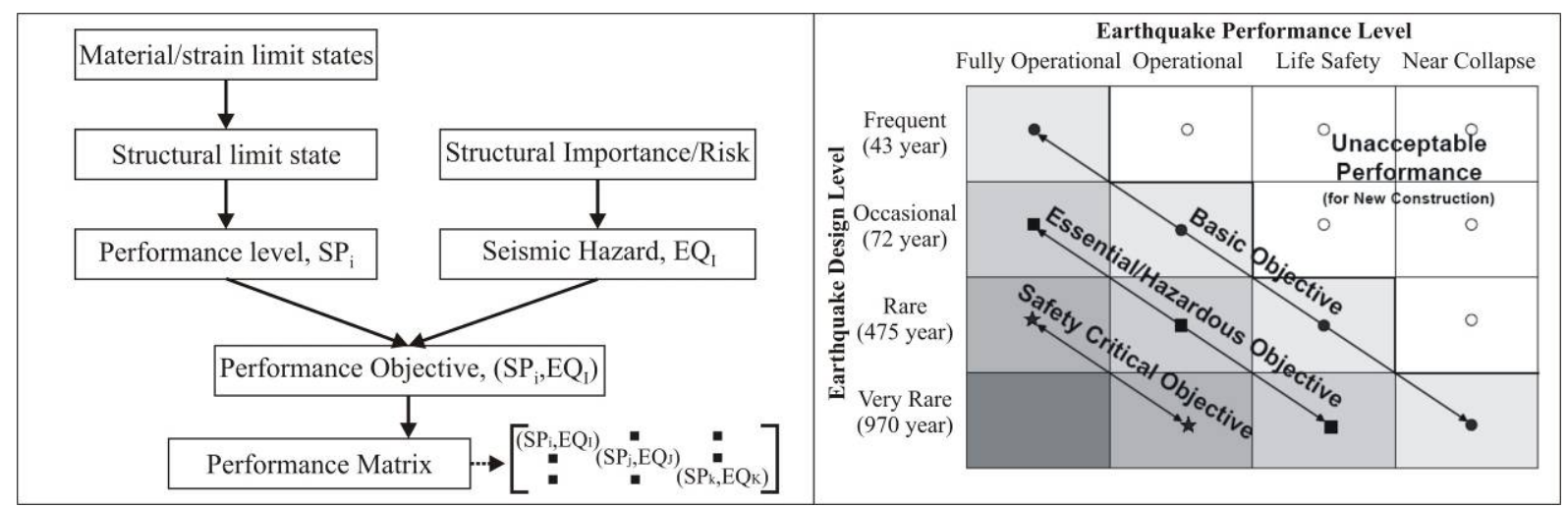

Figure 2. Left: Performance based design flow chart, Right: Performance based design matrix (SEAOC 1999).

The SEAOC blue book (SEAOC 1999) provides a very descriptive performance-based seismic design philosophy. A similar philosophy is incorporated within FEMA 450 (BSSC 2003) for the design of new structures and FEMA 273 (BSSC 1997) and FEMA 356 (ASCE 2000) for the rehabilitation of existing structures. In addition to the documents above, a number of publications have been produced refining the performance-based design philosophy to its current state-ofthe-art (fib 2003a), (fib 2003c), (Priestley et al. 2007).

\subsection{Seismic Hazard (Earthquake Intensity)}

A seismic hazard model is generally adopted within most seismic codes which relate the reoccurrence interval of an earthquake e.g. the return period or a probability of exceedance, to a scaled design spectrum through a seismic risk factor (defined as ' $R$ ' in (NZS1170.5 2004)).
It is interesting to note that a number of codes adopt slight variations for their hazard model relationship. Figure 3 (Left) compares the seismic hazard model of the New Zealand (NZS1170.5 2004), Californian (SEAOC 1999), European (Eurocode: 8 2003) and the U.S. (BSSC 2003) seismic provisions. While they all follow a similar trend, it is important to note the large differences beyond the design level event i.e. return periods greater than $475-500$ years.

Within a performance-based design three or four seismic hazards are generally defined with increasing earthquake intensity, ranging from frequent to very rare (Maximum Considered Event - MCE). FEMA 450 (BSSC 2003) outlines three seismic hazard levels which are used herein and summarised in Table 1. Note that for NZS1170.5 2004 a seismic risk factor of $\mathrm{R}=1.5$ corresponds to a return period of 1,500 years as opposed to 2,500 years for FEMA 450.

Table 1. Seismic hazard levels

\begin{tabular}{ccccc}
\hline Earthquake Intensity & Return period & $\begin{array}{c}\text { Probability of } \\
\text { exceedence in 50 years }\end{array}$ & $\begin{array}{c}\text { Seismic risk factor } \\
\text { (NZS1170.5) }\end{array}$ & $\begin{array}{c}\text { Adopted seismic risk } \\
\text { factor (FEMA 450) }\end{array}$ \\
\hline Frequent & 72 years & $50 \%$ & 0.43 & 0.5 \\
Rare (Design level 2/3MCE) & 475 years & $10 \%$ & 1.0 & 1.0 \\
Very Rare (MCE) & 2,500 years & $2 \%$ & $1.7-1.8^{1}$ & 1.5 \\
\hline
\end{tabular}

\footnotetext{
${ }^{1}$ For high seismicity, NZ1170.5 imposes an upper limit on the PGA to be used for design and in some cases $R$ may be required to be
} less than 1.8

\subsection{Structural performance limits specific to precast post-tensioned walls}

The structural performance levels encompass a set of structural limit states (generally related to material or ductility limits) and/or displacement (i.e. inter-storey drift) limit states. For post-tensioned pre-cast walls, the following structural performance limit states are identified below and presented graphically in Figure 3 (Right). 


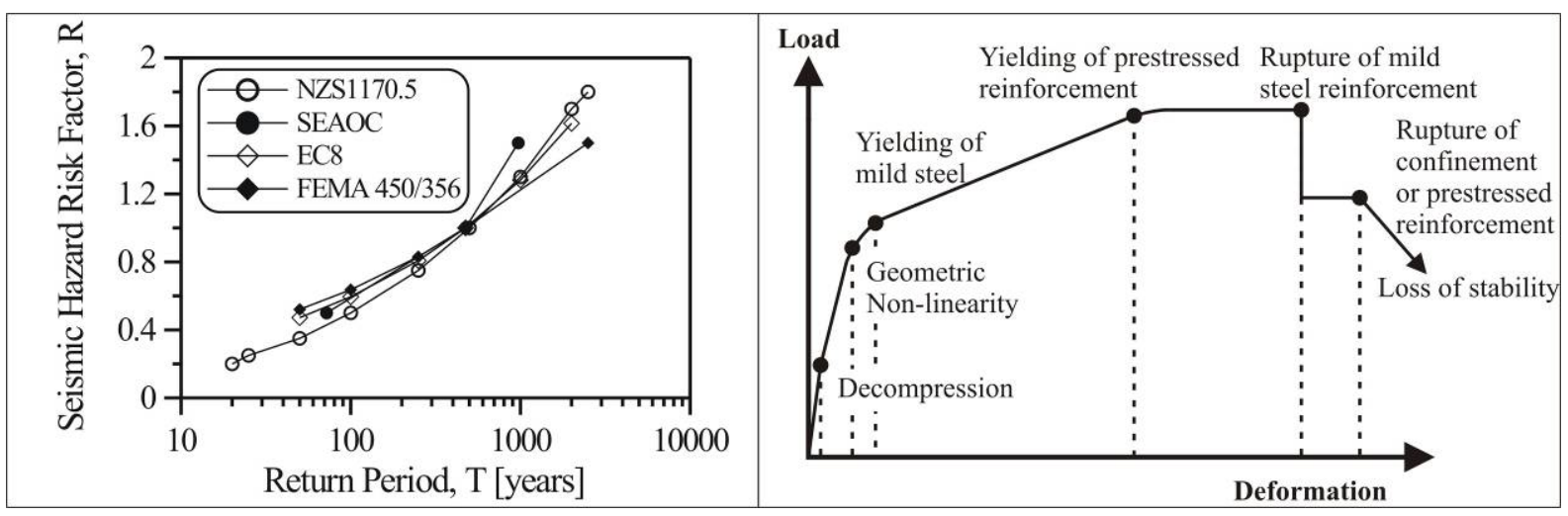

Figure 3. Left: Comparison of the seismic hazard model between various codes, Right: Performance-limit states for precast posttensioned walls

Decompression is the deformation state where the strain at the outer most fibre approaches zero and rotation of the base is initiated. The neutral axis depth $(c)$ is located at the edge of the section $\left(c=L_{w}\right)$, and defines a sudden reduction in stiffness when compared to the gross section stiffness.

Geometric non-linearity occurs when the neutral axis of the section approaches the mid height of the section $\left(c=L_{w} / 2\right)$, and defines a gradual and further reduction in stiffness.

Yielding of the mild steel reinforcement can occur either before or after the geometric non-linearity point depending on the section dimensions and location of the steel reinforcement. Stiffness further reduces with strength continuing to increase due to the elongation of the prestressed reinforcement due to the continued opening of the gap at the base of the wall.

Yielding of the prestressed reinforcement should be treated on a case-by-case basis. Prestressing strands are inherently brittle with little ductile capacity and as a result have little dependable post-yield deformation. The re-centring capacity of the section can be jeopardised if yielding of the prestressed reinforcement occurs due to a reduction of the prestress load, however some permanent displacements may be tolerated for very rare earthquake events. A reduction in the prestress force can be detrimental in some cases - such as a beam-column joint relying on shear transfer through friction at the beamcolumn interface.

Rupture of the mild steel reinforcement can generally be manipulated or controlled for hybrid sections by specifying an appropriate yielding region (unbonded length). Rupture of the mild steel will, in general, not equate to a total loss in stability due to significant redundancy being provided by the posttensioned tendons (and possibly additional mild steel reinforcement that has not yet ruptured). For this reason rupture of the mild steel may be tolerated for rare events. This is especially the case if the dissipation is in the form of external, replaceable devices where the full structural integrity can be reinstated immediately following a major earthquake event.

Rupture of the prestressed reinforcement or confinement reinforcement will result in a sudden loss of lateral stability and will in general define the true ultimate limit of the structure.

Other structural performance limit states include mechanisms resulting from sliding at the rocking interface, shear failure of the wall section and the sliding shear between the precast wall panels, however these can be prevented or minimised considering higher mode effects and over-strength actions.

\subsection{Performance Objectives for post-tensioned precast walls}

Hybrid structures are inherently high performing seismic structures and are generally associated with low damage hence, if designed to achieve a certain performance level, may in fact achieve much higher levels when considering residual deformations, repair and downtime. Following on from FEMA 450 and combining recommendations from elsewhere ((Kurama et al. 1999), (fib 2003c), (Priestley et al. 2007)), three performance objectives are identified for precast posttensioned wall systems (non-structural performance levels are not considered)

Immediate occupancy: Negligible damage to the structural system where, under a very frequent event (return period of 72 years), the dissipaters may or may not have yielded ( $\varepsilon_{\mathrm{s}}$ less than or equal to $\left.\varepsilon_{\text {yield }}\right)$. Concrete strains should be relatively low $\left(\varepsilon_{\mathrm{c}}\right.$ less than 0.004$)$, and the tendons should be within their linear elastic limit. At this limit state permanent displacements are negligible.

Damage Control: Significant structural damage has occurred with some loss in strength and stiffness but still retains significant margin against collapse. Some permanent displacements may exist but are minimal. Under a rare earthquake event $(2 / 3 \mathrm{MCE}$ level) the dissipaters may exceed yield (some dissipaters may have in fact ruptured) and rupture should be avoided $\left(\varepsilon_{\mathrm{s}}\right.$ less than 0.05 or $\left.0.06 \varepsilon_{\mathrm{su}}\right)$. Yielding of the tendons is to be avoided to ensure significant margin against collapse and to control residual displacements Appendix B of the New Zealand concrete code specifies $\varepsilon_{\mathrm{pt}}$ to be less than $0.9 \varepsilon_{\text {pt,yield }}$. The concrete strains are well within the non-linear range $\varepsilon_{\mathrm{c}}=0.02$ but can be accommodated through proper detailing of the rocking section (stirrup confinement and/or additional steel confining plates located at the edge of the wall section).

Collapse prevention: The gravity load carrying capacity of the structural system is maintained. Structural damage is significant and a majority of the stiffness is lost, combined with some loss in strength. Some permanent displacements are tolerated. Under a very rare earthquake (MCE level event) a majority of the dissipaters may have ruptured (if rupture is to be prevented $\varepsilon_{\mathrm{s}}$ should be less than 0.08 ). The tendons may yield but should not exceed rupture ( $\varepsilon_{\mathrm{pt}}$ less than $\varepsilon_{\mathrm{pt}, \mathrm{u}}$ ). Furthermore the integrity of the confined concrete core can be maintained by preventing rupture of the confinement reinforcement through limiting the concrete strains to 1.5 times that above (Priestley et al. 2007).

Furthermore, shear failure of the section and slip of the precast 
wall panels should be avoided, while preventing slip between the foundation and the rocking interface will ensure a more reliable performance.

\subsection{Design considerations for retrofit of existing frame buildings using post-tensioned walls}

The above performance objectives are specific to posttensioned walls alone. In a retrofit intervention, where a posttensioned wall is located in line with an existing reinforced concrete frame, creating a dual system, the performance objectives must consider the system as a whole. Performance limit states are likely to be governed by the performance limit states of the existing building. Each structural element must be considered i.e. beams, columns, beam-column joints etc, with each structural element having its own structural performance limits. Following an assessment of the existing building to determine a hierarchy of strength and failure mechanism, a set of performance limit states can be defined at each of the beam column joints regions. A performance-based retrofit procedure which limits the deformation of the most critical structural elements to allowable levels i.e. joint rotations and/or member curvatures, has be proposed in a previous publication (Marriott et al. 2007a). Further details of performance limit states for existing buildings are available in the literature within the following documents; FEMA 356 (ASCE 2000), fib Bulletin 24 (fib 2003b) and the NZSEE guidelines (NZSEE 2005).

The post-tensioned wall system tested herein was considered as a retrofit solution for an existing, 3-storey, prototype RC frame building. An assessment of the prototype building, considering principal tensile joint stresses, revealed that the beam-column joint was the critical element at almost every joint. The design therefore targeted an inter-storey drift of $1 \%$ corresponding to a moderate level of joint damage. Depending on the reinforcement joint detailing, at this level the exterior beam-column joints are likely to suffer some strength degradation but repair should be possible. Furthermore, under a very rare event, a limiting inter-storey drift of $1.5 \%$ would ensure that while extensive damage to the exterior joints would result in a significant reduction in capacity (and possibly irreparable damage), the gravity load carrying capacity of the joint, and hence the frame, should be maintained. In fact, the loss in lateral capacity of the frame due to the deterioration of the exterior beam-column joints will be compensated for by the increase in lateral capacity of the post-tensioned wall (high post-yield stiffness inherent of post-tensioned systems).

\section{EXPERIMENTAL PROGRAMME}

An extensive experimental programme was undertaken at the University of Canterbury to investigate both the cyclic and dynamic performance of post-tensioned rocking wall systems with alternative dissipation mechanisms.

The experimental programme is divided in two phases, in Phase I the high speed cyclic response of post-tensioned rocking wall systems is investigated at increasing levels of amplitude and frequency from $0.1 \mathrm{~Hz}$ through to $2.0 \mathrm{~Hz}$.

In the second phase the dynamic response was investigated through free vibration testing and earthquake excitation. The dynamic testing was concerned with the response of the wall units to both near-field and far-field ground motions to investigate the effectiveness of velocity dependant and displacement dependant dissipation. This paper focuses on the experimental response of the post-tensioned walls subjected to earthquake excitation.

The shake-table test setup is presented in Figure 4. The mass of the system was provided via a $3,840 \mathrm{~kg}$ concrete block suspended by the workshop crane. This pendulum system proved very effective in providing a consistent driving mass. Furthermore, the mass was monitored about 5 degrees of freedom to ensure a majority of the energy was transmitted in the principal direction of motion. Out-of-plane restraint of the wall was provided by rigid steel channels with rollers located between the wall and the steel channels to prevent friction entering the system.

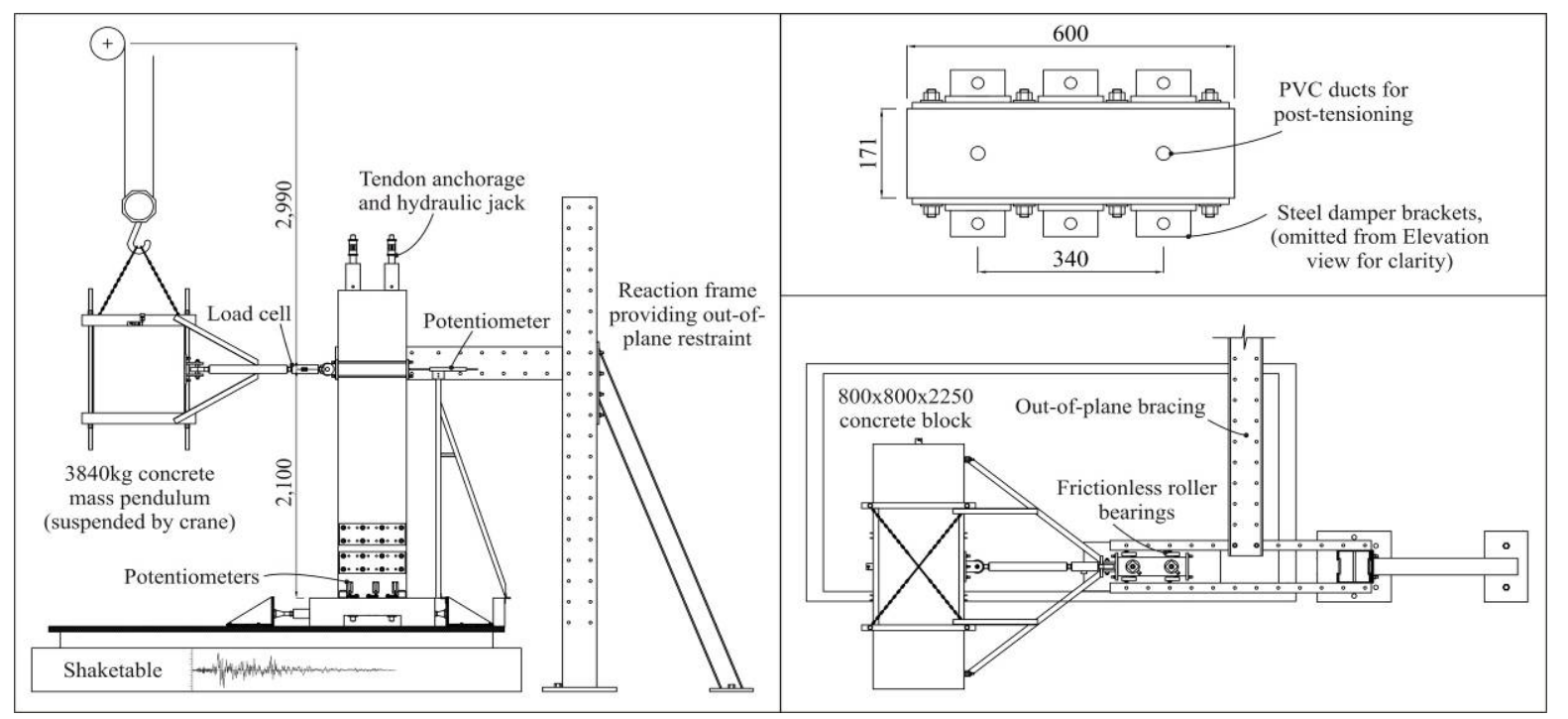

Figure 4. Shake-table test setup; Left: Front elevation of the experimental test, Top Right: Section plan of the precast wall section, Bottom Right: Plan view of the experimental test.

\section{CONSTRUCTION DETAILS OF THE POST- TENSIONED WALL UNITS}

A total of five wall units were tested with or without dissipation and consisting of viscous devices, mild steel tension-compression-yielding devices (TCY devices) or a combination of both viscous and mild steel devices. All five wall units were post-tensioned, such that their monotonic 
backbone envelopes were similar. Due to space limitations, the results of four wall units are presented herein. A summary of the wall units are presented in Table 2 outlining the posttensioning details and dissipation content.

Table 2. Wall test unit details

\begin{tabular}{ccc}
\hline Test & Post-tensioning details & Damper device details \\
\hline $\mathbf{H Y}_{\mathbf{0 M S}-0 \mathrm{~V}}$ & 2 tendons each stressed to $50 \mathrm{kN}$ & - \\
$\mathbf{H Y}_{\mathbf{0 M S}-4 \mathrm{~V}}$ & 2 tendons each stressed to $30 \mathrm{kN}$ & \\
$\mathbf{H Y}_{\mathbf{2 M S}-4 \mathrm{~V}}$ & 2 tendons each stressed to $20 \mathrm{kN}$ & 4 viscous dampers (supplied by FIP Industriale) \\
$\mathbf{H Y}_{\mathbf{2 M S - 0 V}}$ & 2 tendons each stressed to $40 \mathrm{kN}$ & 4 viscous dampers plus 2 TCY mild steel dampers \\
\hline
\end{tabular}

Details of the TCY mild steel dampers and the viscous dampers in presented in Figure 5. Typical axial load versus axial displacement graphs for each are also shown. The viscous dampers used in this investigation were highly nonlinear, resulting in a relatively small velocity dependency on the damper force. Both devices provide very stable dissipation; specifically the TCY mild steel damper provides very stable behaviour when loaded in compression confirming the efficiency of the anti-buckling steel tube system adopted.

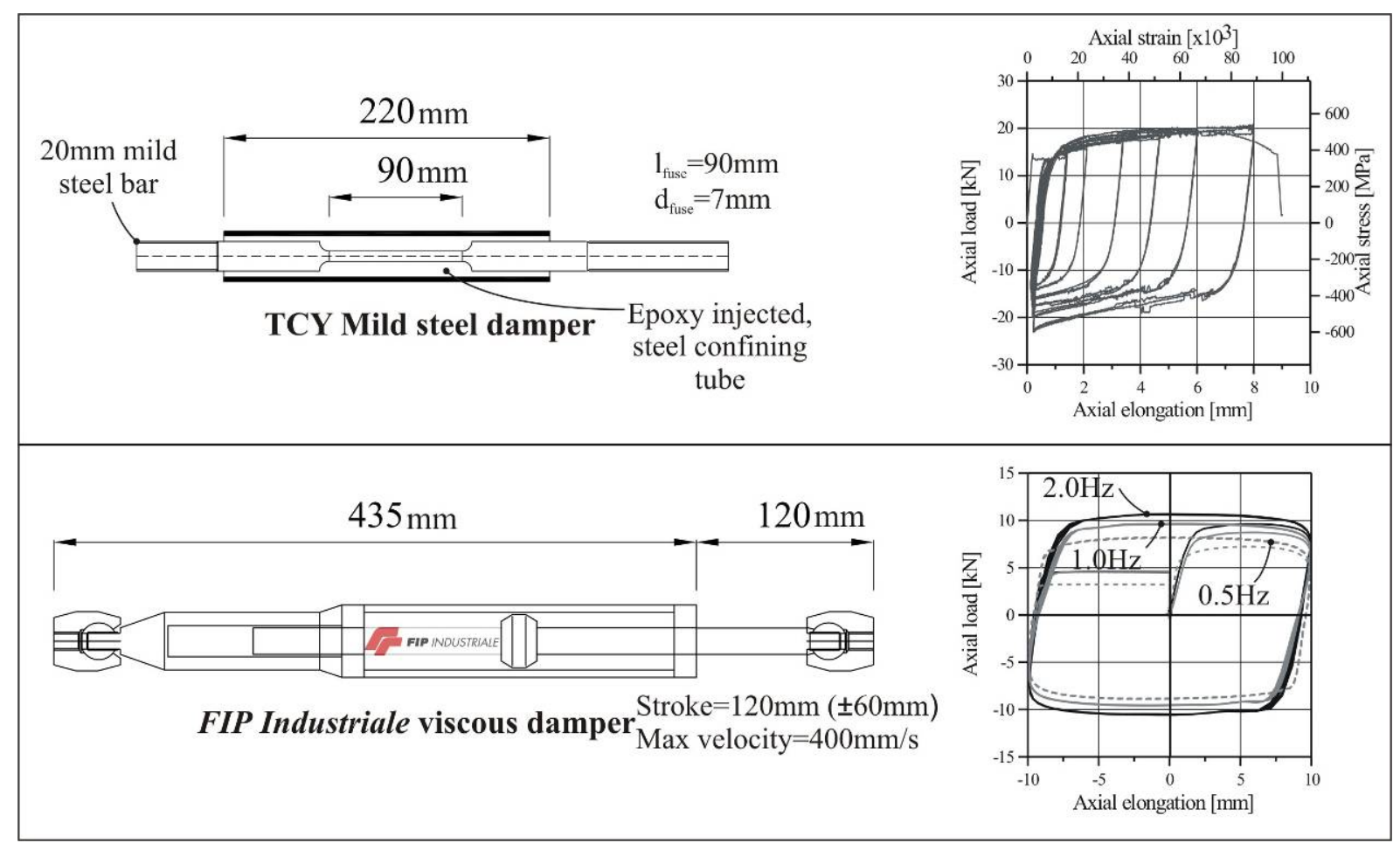

Figure 5. Damper details; Top: TCY mild steel damper, Bottom: FIP Industriale viscous damper.

Details of the four wall units are further illustrated in Figure 6. Wall unit $\mathrm{HY}_{0 \mathrm{MS}-\mathrm{ov}}$ has no dissipation devices and relies on contact damping alone, $\mathrm{HY}_{0 \mathrm{MS}-4 \mathrm{~V}}$ comprises of 4 viscous dampers (supplied by FIP Industriale), $\mathrm{HY}_{2 \mathrm{MS}-4 \mathrm{~V}}$ comprises of
4 viscous dampers and 2 TCY mild steel dampers (fabricated in-house) and $\mathrm{HY}_{2 \mathrm{MS}-0 \mathrm{~V}}$ comprises of $2 \mathrm{TCY}$ mild steel dampers. 


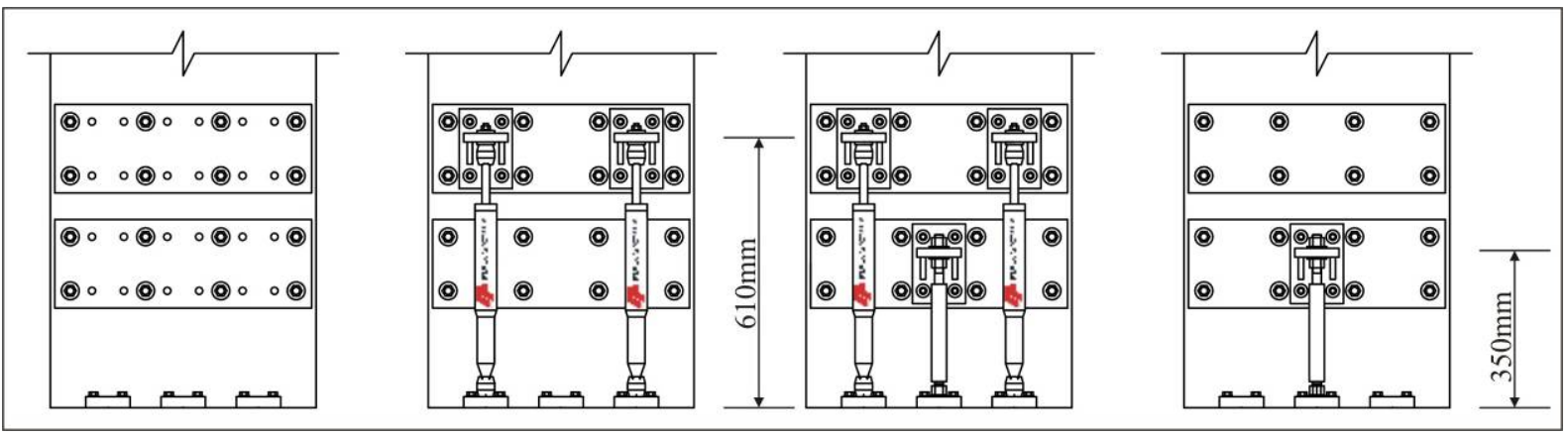

Figure 6. Wall units; Left: Unit HY ${ }_{0 M S-0 V}$, Centre Left: Unit HY $Y_{0 M S-4 V}$, Centre Right: Unit HY ${ }_{2 M S-4 V}$, Right: Unit HY $Y_{2 M S-0 V}$.

\section{CONSTRUCTION PROCESS OF THE PRECAST WALL UNIT}

\subsection{Precast concrete wall and foundation construction}

Construction details of the precast wall were typical of precast construction with the inclusion of two PVC ducts running the height of the wall to locate the unbonded tendons. A fabricated steel plate confining toe was cast within the precast unit (Figure 7: Top Left and Right). This confining bracket would limit and prevent any damage to the concrete around the toe region as the wall rocked from toe to toe. The precast foundation was constructed with a pocket on the underside to allow access to the anchorages for the post-tensioned tendons. A recess was also cast into the top of the foundation to accommodate the precast wall (Figure 7: Bottom Left and Figure 8: Left). When the wall was lowered into position and located within the foundation recess, a high flow epoxy grout (Sikadur 42) was pumped under pressure beneath the rocking interface (Figure 8: Right). This provided ample shear transfer between the wall and foundation whilst also preventing slip along the rocking interface.
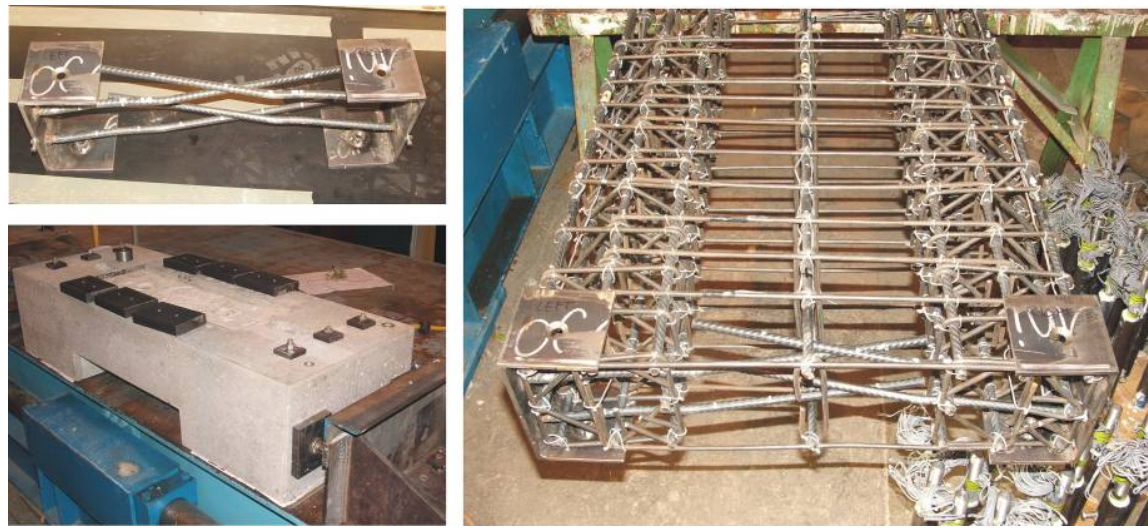

Figure 7. Construction of the precast wall unit and precast foundation; Top Left: Steel confining plates, Bottom Left: Precast foundation, Right: Wall reinforcement.
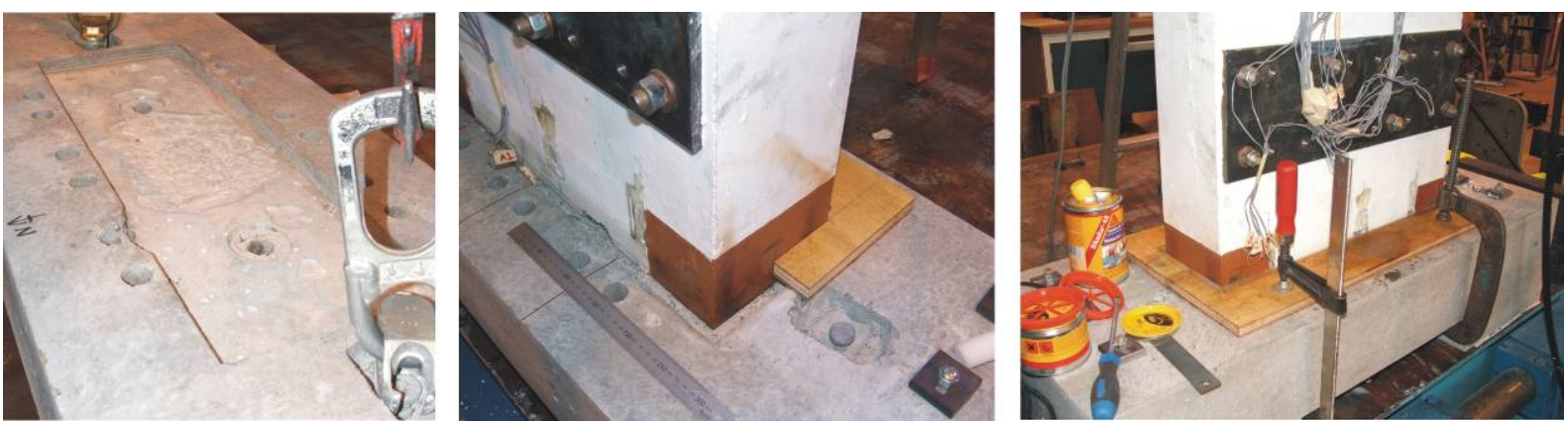

Figure 8. Construction detail of the rocking interface; Left: $18 \mathrm{~mm}$ recess cast into precast foundation, Centre: Location of the precast wall within recess, Right: Grouting of the rocking interface.

\subsection{Connection details of the external devices}

The external devices were connected to the wall by stiff steel brackets. These steel dissipater brackets were bolted to a steel plate which was fixed rigidly to side of the precast concrete wall. The construction of this rigid steel plate connection is 
shown in Figure 9: the surfaces of the steel plates and the concrete wall were sufficiently roughened and a layer of high strength epoxy (Hilti RE 500) was applied to both surfaces. The steel plate was located in position and 8 high strength $(880 \mathrm{MPa})$ threaded rods were tightened to $65 \%$ of their proof load to enable the damper forces to be transferred to the wall via friction/mechanical interlock with essentially zero slip. Two steel plates per face on the wall provided a total of 6 damper locations (per face) by which to install either the viscous or TCY steel dampers.
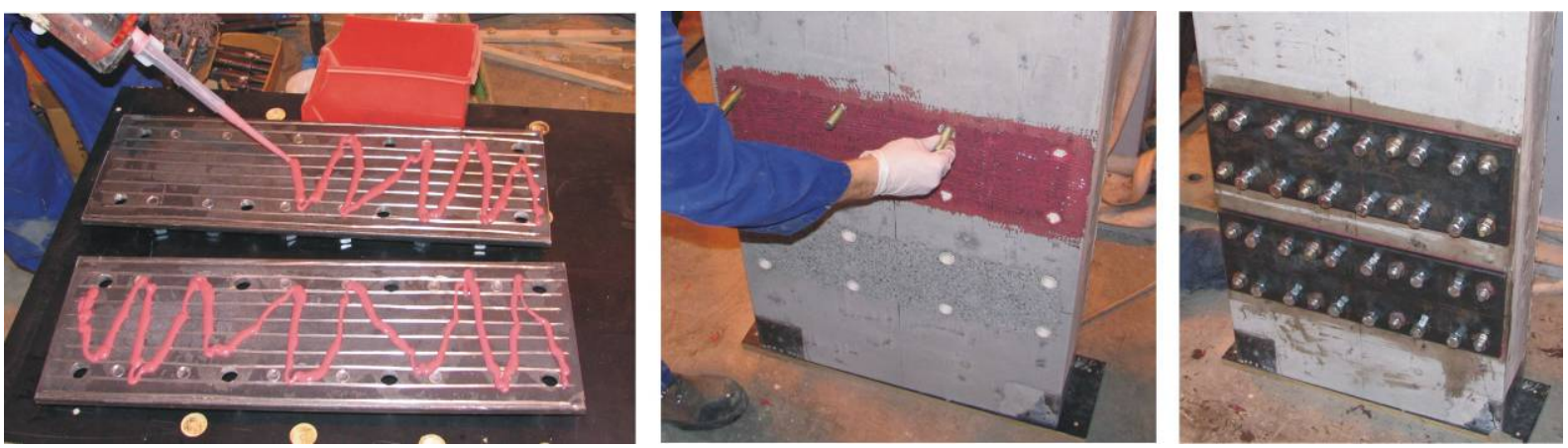

Figure 9. Damper connection details; Left: Preparation of the steel plate - roughening and application of high strength epoxy, Centre: Roughening of the concrete, application of high strength epoxy and location of the high strength threaded rods, Right: Installation of the steel plates - threaded rods tightened to $65 \%$ proof load.

Two of the completed test units are shown in Figure 10; Unit

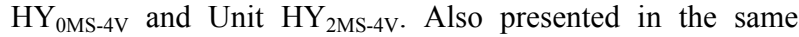
figure are the experimental cyclic results for both units during testing at a frequency of $0.5 \mathrm{~Hz}$. The results are presented in terms of the lateral over-turning moment versus rotation of the base (gap opening). Both wall units indicated very stable and efficient behaviour with no physical damage occurring to either wall unit. The external devices provide an attractive architecture feature illustrating a strong and advanced seismic resisting connection. Furthermore, inspection and replacement of the external damper elements is extremely simple.
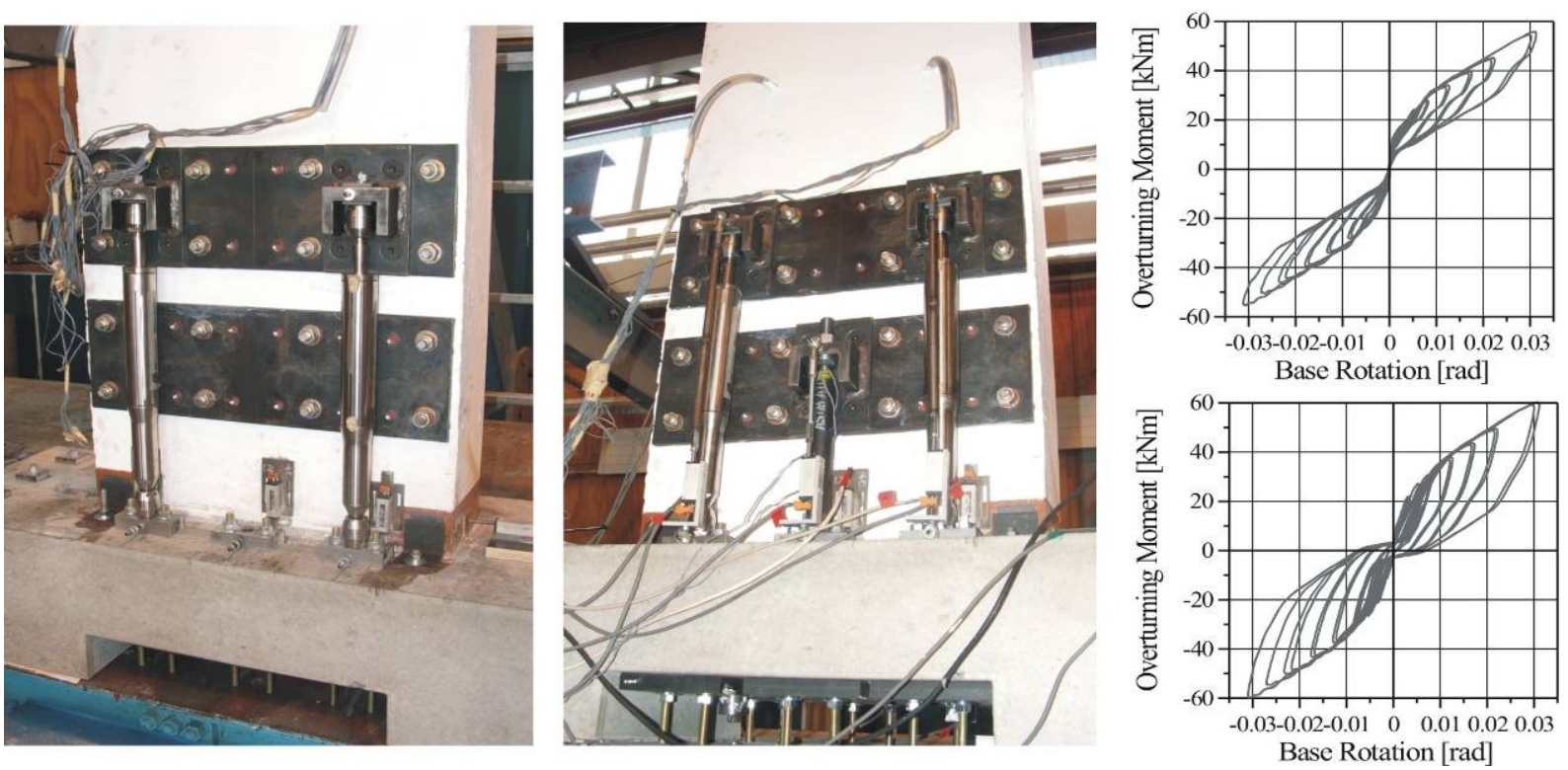

Figure 10. As-built wall units; Left: Unit 2 (4 viscous dampers), Centre: Unit 3 (4 viscous dampers and 2 TCY mild steel dampers), Top Right: Experimental response of $\mathrm{HY}_{2 M S-0 V}($ testing at $0.5 \mathrm{~Hz}$ frequency), Bottom Right: Experimental response of $\mathrm{HY}_{2 M S-4 V}$ (testing at $0.5 \mathrm{~Hz}$ frequency).

\section{SELECTION OF THE EARTHQUAKE RECORDS}

The earthquake records used for this study were based on two seismic hazard levels; rare (2/3MCE) and very rare (MCE). Two earthquake records were chosen for each hazard level; one near-field (NF) and one far-field (FF). As an example, the MCE far-field event is identified as EQ-MCE_FF.

The earthquake records were scaled to the New Zealand seismic design spectrum (NZS1170.5 2004), for $\mathrm{R}=1.0$ for $2 / 3 \mathrm{MCE}$ and $\mathrm{R}=1.5$ for MCE. Details of each earthquake record used for the study are summarised in Table 3. The chosen records required careful consideration as the shaketable at the University of Canterbury has a limiting output velocity of approximately $240 \mathrm{~mm} / \mathrm{s}$ - when considering a similitude scale factor of $1 / 3$, spectrum-scaled earthquake records could not exceed a velocity of $415 \mathrm{~mm} / \mathrm{s}$ without record modification. This proved extremely difficult in terms of locating appropriate near field earthquake records. It was to this end that records EQ-2/3MCE NF, EQ-MCE FF and EQMCE_NF required some record modification as their ground velocities slightly exceeded the limitation of the shake-table this record modification procedure truncates the velocity at $235 \mathrm{~mm} / \mathrm{s}$ to avoid unwanted acceleration spikes. The details 
of the record modification procedure are outside the scope of this paper, however details can be found in (Chase et al. 2005).

The acceleration response spectrum for each of the records and the corresponding New Zealand design spectrum (both $\mathrm{R}=1.0$ and $\mathrm{R}=1.5$ ) are provided in Figure 11. The design spectrum corresponding to the $2 / 3 \mathrm{MCE}$ level represents a seismic hazard having $\mathrm{R}=1$ (500 year return period for building importance level 2), soil category $\mathrm{C}$, and $\mathrm{S}_{\mathrm{p}}=0.7$ located in Wellington within $2 \mathrm{~km}$ of a major fault. The records were scaled over a period range of $0.45 \mathrm{~s}$ to $1.0 \mathrm{~s}$ following a displacement-based retrofit procedure.

Table 3. Earthquake records used for shake-table tests

\begin{tabular}{cccccc}
\hline & Earthquake record & Recording Station & $\begin{array}{c}\text { Scaled } \\
\text { PGA }\end{array}$ & $\begin{array}{c}\text { Scaled PGV } \\
{[\mathbf{m m} / \mathbf{s}]}\end{array}$ & Scale factor \\
\hline EQ-2/3MCE_FF & Kobe & Sakai & 0.256 & 276 & 1.633 \\
EQ-2/3MCE_NF & Loma Prieta & Saratoga-W Valley & 0.220 & 408 & 0.663 \\
EQ-MCE_FF & Cape Mendocino & Rio Dell Overpass & 0.382 & 434 & 0.992 \\
EQ-MCE_NF & Northridge & La Dam & 0.364 & 530 & 1.044 \\
\hline
\end{tabular}
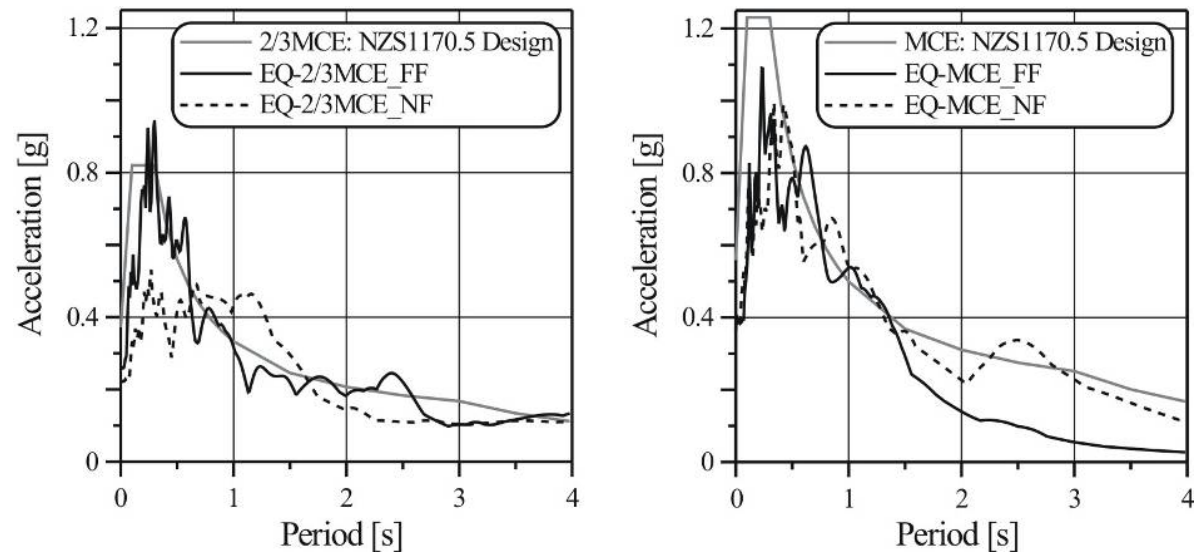

Figure 11. Scaled acceleration response spectrum and NZS1170.5 elastic design spectrum; Left: 2/3 MCE, Right: MCE.

\section{SHAKE-TABLE RESPONSE}

The maximum lateral displacement, (theoretical) compression strain, tendon strain and damper displacement is presented for each of the wall units when subjected to each of the four table records in Table 4 (two EQ records for each seismcity). It should be noted that the concrete compression strains presented in Table 4 were not directly measured, but calculated using a global member compatibility condition for rocking systems with external devices (Marriott et al. 2007b). For all four wall units the design lateral drift of $1.0 \%$ was respected at the design level event, being the $2 / 3 \mathrm{MCE}$, i.e. the 500 year return event. In fact the largest displacement for all four of the wall units at the design level seismic hazard was $1.07 \%$ of lateral drift - while this slightly exceeds the design objective, it was recorded for $\mathrm{HY}_{0 \mathrm{MS}-\mathrm{OV}}$ relying on contact damping alone.

To reduce space, the graphical response of each of the four wall units $\left(\mathrm{HY}_{0 \mathrm{MS}-0 \mathrm{~V}}, \mathrm{HY}_{0 \mathrm{MS}-4 \mathrm{~V}}, \mathrm{HY}_{2 \mathrm{MS}-0 \mathrm{~V}}\right.$ and $\left.\mathrm{HY}_{2 \mathrm{MS}-0 \mathrm{~V}}\right)$ is only presented for the MCE earthquake records (EQ-MCE FF and EQ-MCE_NF). The graphical response in Figure $1 \overline{4}$ is presented in terms of the lateral displacement time history and lateral displacement versus base shear response. In Figure 14 the displacement time-history can be compared directly with the design drift objective at the MCE seismic hazard (i.e. maximum allowable drift of $1.5 \%$ ). Each wall satisfied the $1.5 \%$ drift limit with the exception of $\mathrm{HY}_{0 \mathrm{MS}-4 \mathrm{~V}}$ - in this case the limit was exceeded only slightly. The far-field records show the stable force versus displacement nature of each of the dissipating wall solutions, while the near-field records indicate less intensity (directly related to the velocity limit of the shake-table). Of the four walls, $\mathrm{HY}_{2 \mathrm{MS}-4 \mathrm{~V}}$ damps out the response far more effectively when compared to the other units - from a fatigue point of view, this can be very beneficial.

With respect to the performance objectives discussed above for post-tensioned walls, the material limit states were met. For EQ-2/3MCE_FF and EQ-2/3MCE_NF (being the 2/3MCE design seismic hazard), steel strains were below 0.05 , the tendon strains were below $0.9 \varepsilon_{\text {pt,yield }}$ and the concrete strains were well below 0.02. For EQ-MCE_FF and EQ-MCE_NF (being the MCE design seismic hazard), steel strains did not exceed 0.08 , nor did the tendons rupture. Furthermore, the concrete strains were well within the allowable limits.

With respect to the performance objectives related to the frame-wall retrofit system, deformation limit states for the frame, and hence the joint, were only slightly exceeded. The largest recorded lateral drift of $1.07 \%$ for the $2 / 3 \mathrm{MCE}$ seismic hazard level would suggest that the structural integrity of the exterior beam-column joints would be maintained and could be appropriately repaired if necessary. At the MCE seismic hazard level, the maximum lateral drift recorded was $1.67 \%$. The structural integrity of the exterior beam-column joints would be significantly compromised, with very little residual capacity, however the gravity load carrying capacity of the frame should be maintained and local collapse would be 
prevented - repair of the exterior joints is unlikely to be feasible.

While all four units have comparable strength, each unit differs in dissipation content. The lateral displacement versus base shear plots indicates comparatively low dissipation for Unit $\mathrm{HY}_{0 \mathrm{MS}-4 \mathrm{~V}}$ having four viscous dampers. In fact, the viscous devices are quite inefficient for low damper displacement amplitudes due to some clearance tolerances within the end connections of the viscous device. Furthermore, while the nonlinear viscous dampers are relatively independent of velocity, for low velocities the force in the damper has some significant dependency - considering the table velocity limitation, and the method in which the dampers were used, the dampers were operating at around $22 \%$ of their maximum rated design velocity for the largest of the earthquake records (EQ-MCE_FF).

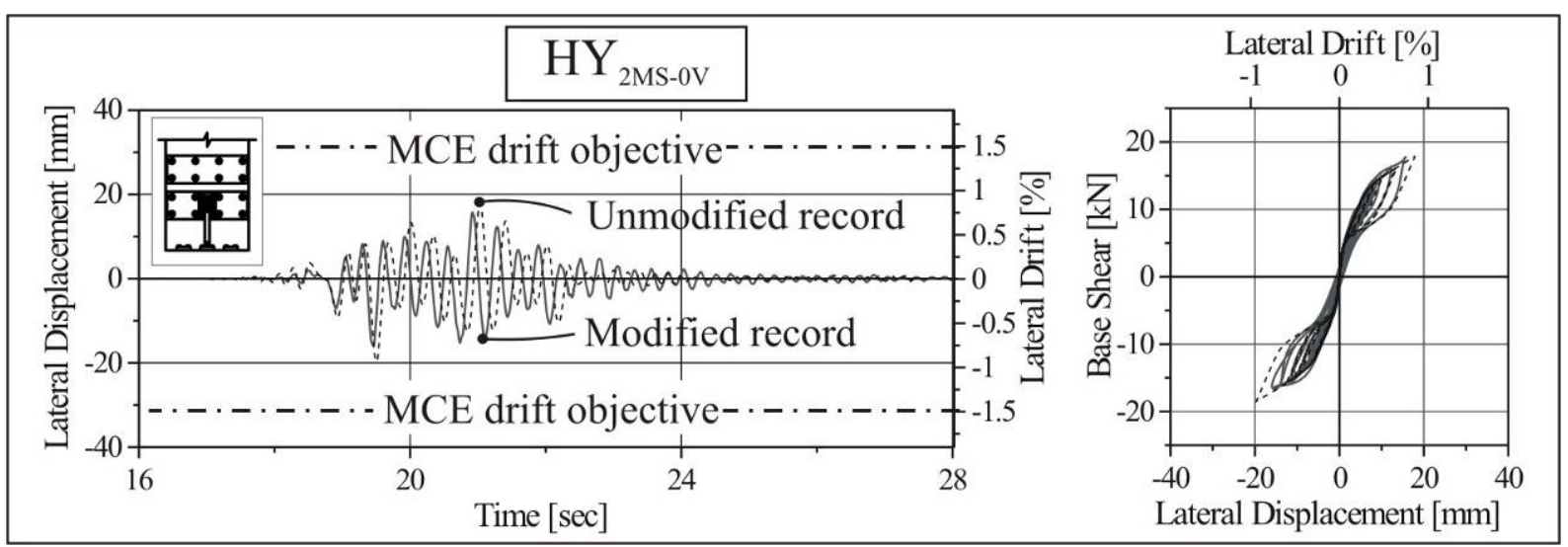

Figure 12. Response of HYOMS-0V to the modified record (experimental test) and unmodified record (numerical analysis).

Table 4. Maximum response parameters; lateral displacement, theoretical concrete compression strain, tendon strain and damper displacement (for viscous devices) or damper strain (for TCY dampers).

\begin{tabular}{|c|c|c|c|c|c|c|}
\hline Record & Wall unit & $\Delta_{\max }[\mathbf{m m}]$ & $\varepsilon_{\mathrm{c}}$ & $\varepsilon_{\mathrm{pt}}$ & $\Delta_{\text {viscous }}$ & $\varepsilon_{\mathrm{ms}}$ \\
\hline \multirow{4}{*}{ 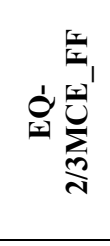 } & $\mathrm{HY}_{00}$ & $22.4(1.07 \%)$ & 0.00056 & 0.00357 & - & - \\
\hline & $\mathrm{HY}_{04}$ & $18.0(0.86 \%)$ & 0.00046 & 0.00240 & 3.3 & - \\
\hline & $\mathrm{HY}_{24}$ & $12.9(0.61 \%)$ & 0.00056 & 0.00163 & 2.3 & 0.01411 \\
\hline & $\mathrm{HY}_{20}$ & $8.5(0.40 \%)$ & 0.00060 & 0.00240 & - & 0.00722 \\
\hline \multirow{4}{*}{ 它空 } & $\mathrm{HY}_{00}$ & $2.9(0.14 \%)$ & 0.00020 & 0.00261 & - & - \\
\hline & $\mathrm{HY}_{04}$ & $8.1(0.38 \%)$ & 0.00045 & 0.00191 & 1.4 & - \\
\hline & $\mathrm{HY}_{24}$ & $9.1(0.43 \%)$ & 0.00058 & 0.00143 & 4.6 & 0.00878 \\
\hline & $\mathrm{HY}_{20}$ & $4.7(0.22 \%)$ & 0.00041 & 0.00221 & - & 0.00278 \\
\hline \multirow{4}{*}{ 空 } & $\mathrm{HY}_{00}$ & $27.6(1.31 \%)$ & 0.00072 & 0.00387 & - & - \\
\hline & $\mathrm{HY}_{04}$ & $35.0(1.67 \%)$ & 0.00082 & 0.00342 & 7.1 & - \\
\hline & $\mathrm{HY}_{24}$ & $27.6(1.32 \%)$ & 0.00091 & 0.00244 & 5.4 & 0.03422 \\
\hline & $\mathrm{HY}_{20}$ & $28.7(1.37 \%)$ & 0.00099 & 0.00351 & - & 0.03533 \\
\hline \multirow{4}{*}{ 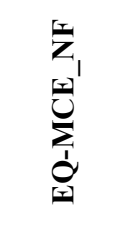 } & $\mathrm{HY}_{00}$ & $20.4(0.97 \%)$ & 0.00062 & 0.00345 & - & - \\
\hline & $\mathrm{HY}_{04}$ & $16.6(0.79 \%)$ & 0.00043 & 0.00230 & 3.1 & - \\
\hline & $\mathrm{HY}_{24}$ & $12.5(0.59 \%)$ & 0.00061 & 0.00159 & 2.1 & 0.01256 \\
\hline & $\mathrm{HY}_{20}$ & $16.0(0.76 \%)$ & 0.00069 & 0.00278 & - & 0.01689 \\
\hline
\end{tabular}

As mentioned above a number of the earthquake records required modification in order to satisfy the velocity capacity of the table (particularly for the near-field records). Figure 12 shows the response of $\mathrm{HY}_{2 \mathrm{MS}-0 \mathrm{~V}}$ to the MCE near-field record
EQ-MCE NF and compares the response of the original unmodified record (using a numerical model) to the modified record (experimental testing). While not discussed herein, the model used for the numerical analysis accurately captures the 
response of $\mathrm{HY}_{2 \mathrm{MS}-\mathrm{OV}}$ when subjected to the modified record and therefore the response under the unmodified record could be predicted with confidence. The maximum displacement response under the unmodified record (numerical model) was found to be $19.7 \mathrm{~mm}(0.94 \%$ drift $)$ which is $23 \%$ greater than the maximum measured displacement of $16.0 \mathrm{~mm}(0.76 \%$ drift) under the modified record (experimentally tested). When the NZS1170.5 elastic design spectrum is scaled to the modified response spectra, the modified near-field record no longer represents a MCE event, instead it approximates an $85 \% \mathrm{MCE}$ event (seismic risk factor, $\mathrm{R}=1.27$ ). It is interesting to note that even considering the unmodified record, the response under the selected near-field records is still lower than that of the far-field records. In fact, the record selection process was such that near-field records with velocity pulses typically greater than $1,000 \mathrm{~mm} / \mathrm{s}$ were required to be avoided, resulting in records which lacked high velocity-pulse characteristics.

Typical of near field records, the acceleration response spectrum of EQ-2/3MCE_NF and EQ-MCE_NF was difficult to scale to the New Zealand spectrum - especially within the short period range. Depending on the period range to which the records were scaled, could result in an artificial reduction in the scaling of the near-field records and hence a reduced response could be expected. However, as discussed above, considering the shake-table velocity limitation, more intense near-field records were unable to be used in any case.

Of the four wall units, $\mathrm{HY}_{2 \mathrm{MS}-4 \mathrm{~V}}$ could guarantee a superior level of protection for each seismic hazard level - especially when considering the response to both the near-field and farfield events. Given that the viscous dampers could be more appropriately used (dampers with lower design velocities), an even higher level of performance could be expected. This confirms the higher performance of 'Advanced Flag Shape' solutions having a combination of velocity and displacement dependant devices, which was previously limited to analytical studies.

Finally, it could be suggested that for relatively stiff structures, a wall system based on strength alone (with minimal dissipation) such as the post-tensioned only solution ( $\mathrm{HY}_{0 \mathrm{MS}}$ ${ }_{0}$ ) can be used to provide similar performance when compared to the other wall units. While in general the measured displacements of $\mathrm{HY}_{0 \mathrm{MS}-\mathrm{OV}}$ were slightly larger than the dissipating wall units, a further reduction of $\mathrm{HY}_{0 \mathrm{MS}-\mathrm{OV}}$ could be achieved with increased lateral capacity - however higher floor accelerations could be expected.

\subsection{Damage state of the precast wall after testing}

Very minor physical damage was observed for all of the wall specimens during and after testing. The rocking toe regions remained completely intact while, if any cracking up the height of the wall had occurred, it was not visible due to the post-tensioning. At the base of the wall a small dust flume was observed on each of the steel confining plates resulting from expulsion of crushed concrete particles beneath the rocking toe Figure 13 (Left). It was not until the wall was removed from the foundation that any damage could be observed. A small amount of injected epoxy had adhered to the underside of the precast wall which is highlighted in Figure 13 (Right Centre). This resulted in some removal of cover concrete from the precast wall but was relatively superficial, again highlighted in Figure 13 (Left Centre). The dislodged cover concrete was then crushed as the wall rocked from toe to toe and could ultimately contribute (in some small way) to the damped response of the wall.
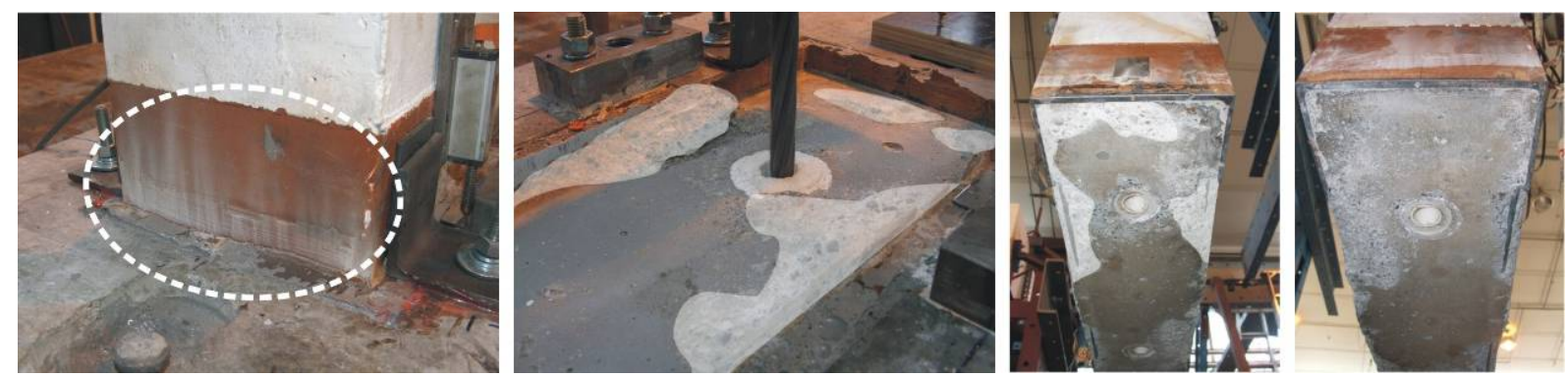

Figure 13. Damage state after removal of the precast wall from the foundation; Left: Dust flume on steel confining plate indicating expulsion of crushed concrete, Left Centre: Foundation recess with residual concrete, Right Centre: Rocking toe region (closest to mass), Right: Rocking toe region (furthest from mass).

\subsection{Contact damping response}

Though not explicitly presented herein, preliminary results have indicated that the amount of dissipation directly associated with the rocking contact damping is minor, in the order of $1-3 \%$ equivalent viscous damping. Therefore, when considering supplementary damping devices, the proportion of contact damping becomes even less of a concern as the damped response is dominated by hysteretic and/or viscous damping. The decision to include contact damping within a model will depend on what type of analysis is required. If the maximum response is the primary parameter i.e. maximum displacements, accelerations and velocities, then the amount of contact damping assigned to the model can have little effect on the output. However, if parameters such as cumulative energy dissipation, cyclic fatigue or information directly relating to the response after the last major excursion, then the proportion of damping and the damping model requires more attention. This response can in fact be quite sensitive to the choice of modelling parameters assigned to the rocking impact, especially for post-tensioned only systems relying on contact damping alone.

It has been found that simple damping models can accurately capture the response of rocking systems, including the peak response and the damped decay response. Preliminary analysis, as part of an ongoing research project, suggests simple damping models proportional to the tangent stiffness are the most accurate in describing the damping in both the non-linear and elastic range. 

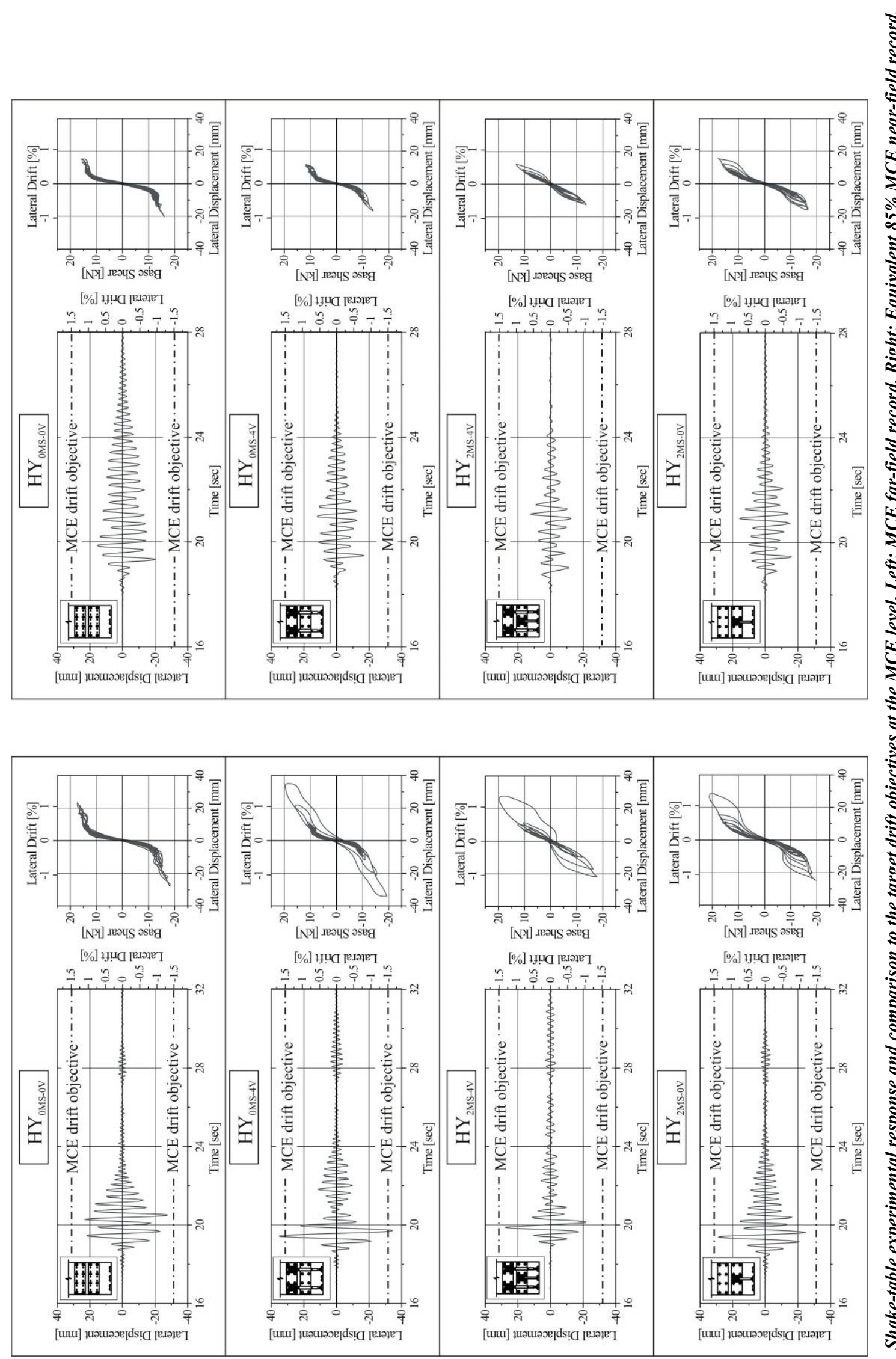

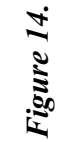




\section{CONCLUSIONS}

Current literature suggests a lack of information related to the dynamic response of post-tensioned precast rocking systems in particular structural walls. This paper presents 16 shaketable tests on four alternative post-tensioned rocking wall systems - each wall was subjected to two near-field and two far-field earthquake records. A prototype post-tensioned precast wall was designed, constructed and dynamically tested based on a retrofit application for a prototype RC frame building. Four post-tensioned walls, each with an alternative dissipation solution were experimentally tested: contact damping alone, viscous damping devices, TCY mild steel devices and a combination of both. The intent was to investigate the performance of post-tensioned wall solutions for use in new design and retrofit where protection against near-field and far-field earthquake events could be ensured through a combination of velocity and displacement dependant devices.

The performance-based design philosophy of post-tensioned precast rocking wall systems is outlined and further reference is made to an existing performance-based retrofit for existing reinforced concrete buildings in order to prevent collapse arising from brittle local failure mechanisms. Performance objectives are discussed relating to post-tensioned wall systems for new design and to the retrofit of existing RC buildings where performance objectives are likely to be governed by the behaviour of critical structural elements within the existing frame i.e. rotations of beam-column joints and/or curvatures of beams and columns.

Following testing scaled to a rare earthquake event having a return period of 500 years, the performance objectives specific to retrofit, were in general, achieved - displacements were slightly exceeded for the system relying on contact damping alone. The target inter-storey drift limit of $1 \%$ suggested that the structural integrity of the exterior joints within the adjoining frame could be maintained, and while suffering minor damage, repair would be possible.

Under a very rare event having a return period of 2,500 years, the performance objectives were again exceeded for the posttensioned only solution. However, the limiting inter-storey drift of $1.5 \%$ should enable the vertical load carrying capacity of the exterior joints to be maintained preventing local collapse. Joint damage is likely to be extensive and repair is unlikely to be feasible.

Advanced Flag Shape solutions consisting of both velocity and displacement dissipation were found to provide a very attractive solution by providing superior protection against the entire suite of earthquake records.

\section{ACKNOWLEDGEMENTS}

Special thanks to Dr Gabriella Castellano of FIP Industriale, Padova, Italy for the use of four viscous damper elements throughout the research programme. Laboratory support from Masoud Maghaddasi during construction and testing and the technical support of John Maley is greatly appreciated. The authors also acknowledge the support from Professor Geoffrey Chase, Geoffrey Rodgers and Kerry Mulligan for technical advice relating to the control of the shake-table.

\section{REFERENCES}

ACI:T1.2-03. (2007). ACI Manual of Concrete PracticeSpecial Hybrid Moment Frames Composed of Discretely Jointed Precast and Post-Tensioned Concrete Members.

ASCE. (2000). Prestandard and Commentary for the Seismic Rehabilitation of Buildings (FEMA 356). Reston, Virginia: Federal Emergency Management Agency.

BSSC. (1997). NEHRP Guidelines for the Seismic Rehabilitation of Buildings (FEMA 273). Washington D.C.: Federal Emergency Management Agency.

BSSC. (2003). NEHRP Recommended Provisions for Seismic Regulations for New Buildings and Other Structures (FEMA 450). Washington D.C.: Federal Emergency Management Agency.

Chase, J. G., Hudson, N. H., Lin, J., Elliot, R. \& Sim, A. (2005). Nonlinear Shake Table Identification and Control for near-Field Earthquake Testing, Journal of Earthquake Engineering. Vol. 9, No. 4, pp. 461-482. July 2005.

fib. (2003a). Displacement Based Seismic Design of Reinforced Concrete Buildings. Lausanne, Switzerland: International Federation for Structural Concrete.

fib. (2003b). Seismic Assessment and Retrofit of Reinforced Concrete Buildings. Lausanne, Switzerland: International Federation for Structural Concrete.

fib. (2003c). Seismic Design of Precast Concrete Building Structures. Lausanne, Switzerland: International Federation for Structural Concrete.

Holden, T. J. (2001). A Comparison of the Seismic Performance of Precast Wall Construction: Emulation and Hybrid Approaches. Christchurch: University of Canterbury.

Kam, W. Y., Pampanin, S., Carr, A. J. \& Palermo, A. (2007). Advanced Flag-Shape Systems for High Seismic Performance including Near-Fault Effects, NZSEE Annual Conference 2007, Palmerston North.

Kurama, Y. C. (2000). Seismic design of unbonded posttensioned precast concrete walls with supplemental viscous damping, ACI Structural Journal, Vol 97(4) 648-658.

Kurama, Y. C. (2002). Hybrid post-tensioned precast concrete walls for use in seismic regions, PCI Journal, Vol 47(5) 3659 .

Kurama, Y. C., Pessiki, S., Sause, R., Lu, L. \& El-Sheikh, M. T. (1998a). Analytical Modelling and Lateral Load Behavior of Unbonded Post-Tensioned Precast Concrete Walls. Lehigh University.

Kurama, Y. C., Sause, R., Lu, L. \& Pessiki, S. (1999). Seismic Behaviour and Design of Unbonded Post-Tensioned Precast Concrete Walls, PCI Journal, Vol 44(3) 72-89.

Kurama, Y. C., Sause, R., Pessiki, S., Lu, L. \& El-Sheikh, M. T. (1998b). Seismic Design and Response Evaluation of Unbonded Post-Tensioned Precast Concrete Walls. Lehigh University.

Mander, J. B. \& Cheng, C.-T. (1997). Seismic Resistance of Bridge Piers Based on Damage Avoidance Design. New York: University of Buffalo.

Marriott, D., Pampanin, S. \& Bull, D. (2007a). Improving the Seismic Performance of Existing Reinforced Concrete Buildings using Advanced Rocking Wall Solutions, NZSEE 2007 Annual Conference, Palmerston North, New Zealand. 
Marriott, D., Pampanin, S. \& Palermo, A. (2007b). Seismic Design, Experimental Response and Numerical Modelling of Rocking Bridge Piers with Hybrid, Post-Tensioned Connections. Christchurch: University of Canterbury.

Mueller, P. (1986). Hysteretic Behaviour of Precast Panel Walls, U.S.-Japan Seminar on Precast Concrete Construction in Seismic Zones, Tokyo, Japan.

NZS3101. (2006). Concrete Structures Standard: Part 1-The Design of Concrete Structures. Wellington: Standards New Zealand.

NZSEE. (2005). Assessment and Improvement of the Structural Performance of Buildings in Earthquake. Department of Building and Housing.

Palermo, A., Pampanin, S. \& Calvi, G. M. (2005). Concept and Development of Hybrid Solutions fro Seismic Resistant Bridge Systems, Journal of Earthquake Engineering, Vol 9(5) $1-23$.

Pampanin, S. (2005). Emerging solutions for high seismic performance of precast/prestressed concrete buildings, Journal of Advanced Concrete Technology, Vol 3(2) 207-223.

Priestley, M. J. N., Calvi, G. M. \& Kowalsky, M. J. (2007). Displacement-Based Seismic Design of Structures. Pavia: IUSS.

Priestley, M. J. N., Sritharan, S., Conley, J. R. \& Pampanin, S. (1999). Preliminary results and conclusions from the PRESSS five-story precast concrete test building, PCI Journal, Vol 44(6) 42-67.

Rahman, A. M. \& Restrepo, J. I. (2000). Earthquake Resistant Precast Concrete Buildings: Seismic Performance of Cantilever Walls Prestressed Using Unbonded Tendons. Christchurch: University of Canterbury.

SEAOC. (1999). Recommended Lateral Force Requirements and Commentary. Structural Engineers Association of California. 